\title{
Dynamics of Large Pelagic Ice Crystals in an Antarctic Ice Shelf Water Plume Flowing Beneath Land-Fast Sea Ice
}

5 Craig Stevens ${ }^{1,2}$, Natalie Robinson ${ }^{1}$, Gabby O'Connor ${ }^{2}$ and Brett Grant ${ }^{1}$

${ }^{1}$ National Institute of Water and Atmospheric Research, Greta Point, Wellington, New Zealand.

${ }^{2}$ University of Auckland, New Zealand.

Correspondence to: Craig Stevens * craig.stevens@ niwa.co.nz

10

\begin{abstract}
Observations of boundary-layer processes and ice crystal behaviour in an outflow region from the Ross/McMurdo Ice Shelves are presented. From a fast ice field camp, we captured the kinematics of free-floating relatively large (many 10 s of $\mathrm{mm}$ in scale) ice crystals that were advecting as well as aggregating in a depositional layer on the sea ice underside (SIPL, sub-ice platelet layer). Simultaneously, we measured the background oceanic temperature, salinity, currents and turbulence structure. At the camp location the total water depth was $536 \mathrm{~m}$, with the uppermost $50 \mathrm{~m}$ being in-situ super-cooled. Tidal flow speeds had an amplitude of around $0.1 \mathrm{~m} \mathrm{~s}^{-1}$ and the resulting under-ice boundary layer sustained turbulent dissipation rates as large as $\varepsilon=10^{-6} \mathrm{~W} \mathrm{~kg}^{-1}$. Acoustic sampling (200 $\mathrm{kHz}$ ) identified three classes of backscatter (1) large individual highly mobile targets, (2) echoes from large, individually identifiable suspended crystals and (3) a varying background, presumably of very small (frazil) crystals. This second class of backscatter was associated with crystal sizes far larger than typical, certainly larger than anything normally described as frazil, and some individuals at least were depositing close to "fully grown". Measurement indicated crystal scales of the range 30-80 mm. The existence and settlement of this scale of crystal has implications for understanding SIPL evolution and the processes controlling the fate of Ice Shelf Water.
\end{abstract}

\section{Introduction}

Regional variability in Antarctic sea ice is a major issue for climate prediction, challenging models (Ludescher et al., 2019) and confounding communication of key issues to stakeholders and decisionmakers. With anthropogenically-induced warming oceans penetrating farther south, increased ice shelf basal melting is expected (Rignot et al., 2013; Kusahara 2020). Relatively warm ocean water penetrates the interior of ice shelf cavities and induces melting on the ice underside. One driver of sea ice variability is the feed-back effect of meltwater exiting major ice shelf cavities (e.g. Holland et al., 2007; Langhorne et al., 2015). The resulting water is at the local freezing point temperature, as dictated by pressure and salinity. This water mixes with the ambient ocean resulting in a fresher, cold seawater 
plume that seeks out the fastest upward flow path on the shelf underside subject to the Coriolis force and basal slope (MacAyeal 1985; Jenkins and Bombusch 1995; Smedsrud and Jenkins 2005; Stevens et al., 2020). These plumes will grow with sustained melting and/or decay with re-freezing removing their thermal deficit. If the plume persists sufficiently to reach the ice shelf edge it flows out beneath the neighbouring sea ice margin (Fer et al., 2012; Langhorne et al., 2015). At this point the basal slope driver of flow ceases and the persistence of the supercool plume is controlled by initial buoyancy, growth of new ice, topography and mixing (Hughes et al., 2014). This step represents a critical phase in the passage of basal melt water where the greatest changes in drivers and environment are all located. This supercool water drives sea ice growth by absorbing heat into the stratified upper ocean and facilitates the generation and growth of ice crystals (Robinson et al., 2014; McPhee et al., 2016; Hoppmann et al., 2020).

There is evidence that in some settings this ice formation occurs as buoyant crystals in the water column (Hoppmann et al., 2015; 2020; Frazer et al., 2020). If these crystals grow slowly, remaining sufficiently small that viscosity dominates, then they are mainly passively advected. Typically, this is the scale $(<1 \mathrm{~mm})$ at which crystals are thought to exist. However, if they grow sufficiently large whilst suspended, then buoyancy-driven thin disk mechanics must dominate their trajectory (Jordan et al., 2015). The extent of a plume has been modelled using schemes that develop and transport crystals, again with a focus on mm-scale crystals (e.g. Holland et al., 2007; Hughes et al., 2014), or if not, then in a "bed-load" and so essentially a part of the ice-ocean interface (Robinson et al., 2014). Sampling challenges make it difficult to build up spatial appreciation of the crystal metrics and growth rate in the SIPL but one correlation that emerges is that SIPL thickness and supercooled seawater are co-located (Langhorne et al., 2015; Brett et al., 2020).

By following the ice shelf water plume as it evolves in space and time, it is possible to look at ice growth and thermal relief (e.g. Smedsrud and Jenkins 2005; Hughes et al., 2014). A recent review by Hewitt (2020) identifies issues like crystal growth, the role of sediments and the limited availability of observations as being key issues for the advancement of understanding at the ice shelf scale. At the larger regional to global scale the challenges lie more with sea ice production and water mass formation as coupled models seek to combine the ocean, atmosphere and ice structure (e.g. Roach et al., 2018; Richter et al., 2020; Moorman et al., 2020). Uniformly these studies identify the need for more observations both at the process, and monitoring, scales.

A decade-long sequence of sea ice camps in the McMurdo Sound region (Robinson et al., 2020) have revealed that these platelets form a coherent layer on the underside of sea ice (a sub-ice platelet layer, SIPL Hunkeler et al., 2015; Wongpan et al., 2015; Hoppmann et al., 2020) - into which they are eventually incorporated (Smith et al., 2001; Langhorne et al., 2015). The McMurdo Ice Shelf, a small ice shelf that sits between the Ross Ice Shelf (the largest ice shelf on the planet by area) and McMurdo Sound. It includes a region called "the Dirty Ice" because of the substantial rock debris visible on the 
shelf surface and has been described as "perhaps the strangest ice shelf in the world" (Debenham, 1965; Atkins and Dunbar 2009). This material is partly marine in origin, as sediment entrained into the growing marine SIPL on the shelf-underside finds its way to the surface (Campbell and Claridge 2003). This, in itself, is evidence of supercool oceanic conditions.

Hoppmann et al. (2020) review our present understanding of Antarctic platelet ice and makes it clear the topic is still in a discovery phase - partly due to the challenges of making comprehensive observations. At the same time, modelling approaches have needed to advance - creating a tension. It is likely that the deposition and formation of ice crystals at a range of scales influences interfacial momentum transfer, sea ice composition and strength as well as ecological habitat throughout localised parts of Antarctic coastal waters. While geophysical boundary-layers are well understood, a number of questions arise around unique aspects of the present situation and provide a focus for the present study. (1) Is there evidence of large pelagic crystals? (2) Is there a relationship between crystal behaviour and the turbulent under-ice boundary-layer structure? (3) Does sediment from the Dirty Ice influence the mechanics? (4) What are the large-scale implications of such finescale mechanics?

\section{Methods}

\subsection{Location and Camp}

The "K131 sea ice camp" (Antarctica New Zealand logistics event designation, Stevens et al., 2018) was deployed on $2.3 \mathrm{~m}$ thick sea ice from 21 October-4 November 2015 at a location in Southern McMurdo Sound $\left(-77^{\circ} 51.913^{\prime} \mathrm{S}+166^{\circ} 00.053^{\prime} \mathrm{E}\right)$ on an ocean depth of $536 \mathrm{~m}$. At the time of sampling the edge of the fast ice was $\sim 20 \mathrm{~km}$ to the north. The camp location was selected based on surveys of platelet deposition thickness $(1.8 \mathrm{~m})$ whereby there would be sufficient platelets to be measurable (Langhorne et al., 2015), while avoiding too many platelets (i.e. SIPL too deep to easily penetrate a conductivity temperature depth - CTD - profiler through) and also avoiding the substantial tidal currents encountered further towards Haskell Strait (Figure 1a, Stevens et al., 2009; Mahoney et al., 2011). The K131 camp consisted of modified shipping containers with cut-out floors allowing access to the ice and ocean below. A hot-water cutter was used to melt through and remove the sea ice in blocks. It was notable that upon removal of the blocks, the water which filled the hole appeared milky but that this gradually dissipated over the subsequent days. After 12 days of operations and many seal occupations of the holes, the hole water was fully flushed and very clear. We speculate that the water in the hole was initially from the melting of the sea ice and upwards drainage from the SIPL and contained sufficient levels of sediment to be visible but that over time this was replaced with clear ocean water. With regard to the regional sampling context, the present data were collected south of where the later Frazer et al. (2020) acoustic sampling took place. Furthermore, the analysis of under ice 
boundary roughness data synthesis described in Robinson et al. (2017) include some data from the same field camp as here, but with instruments focused on the ice underside.

\subsection{Sub-Ice Platelet Layer (SIPL)}

Upon removal of the blocks of sea ice, the SIPL would remain intact beneath the ice hole, giving an indication of the cohesive strength of the layer. Sampling activity would then penetrate through this SIPL by first lowering a weight to create a hole. Hoppmann et al. (2020) describes the semantics of platelets and frazil. For present purposes we consider them to be ends of a spectrum of the same physical crystal evolutionary process. Crystals were extracted from the SIPL by reaching down with a porous scoop. They would be recovered either as individuals or in clumps. In many instances once extracted the clumps would collapse with very little encouragement indicating only weak interlocking crystal growth. This in part indicates the role of buoyancy aiding maintenance of the SIPL but also suggests that the SIPL is not always a tightly interlocked matrix of crystals. The dimensions of each crystal were then quantified by manual measurement (done immediately to avoid significant melting or growth). It is possible that these represent a distinctly different set of sizes to the suspended pelagic crystals, but large crystals were definitely observed in video rising. It is likely however that this approach is biased towards larger crystals (> $5 \mathrm{~mm}$ diameter). Crystal size data from a nearby camp from the following year $\left(77.8183^{\circ} \mathrm{S} 165.4059^{\circ} \mathrm{E}\right.$, November 2016 - see Robinson et al., 2020) are also included.

\subsection{Video and echosounder records}

While qualitatively very useful, video/visual observations are challenging to interpret quantitatively because of light variability, lens distortion and reflection/viewing angle effects. Additionally, it was difficult to see individual crystals arrive and settle as the light would saturate the camera. Penrose et al. (1994) describe how acoustics provide a more consistent picture of crystal behaviour. We used a Simrad EK60 $200 \mathrm{kHz}$ echo sounder recording acoustic backscatter at $1 \mathrm{~Hz}$ with $4 \mathrm{~cm}$ vertical resolution over a sampling cone that is 7 degrees across so that at a depth of $25 \mathrm{~m}$ the cone is three $\mathrm{m}$ wide. The cone has side-lobes in the upper $5 \mathrm{~m}$ of the water column that are as wide as 30 deg. The beam-width is not particularly critical so long as it is wide-enough that scatterers register some rise component (vertical resolution). With horizontal flows of around $0.05 \mathrm{~m} \mathrm{~s}^{-1}$ this means that a reflector would stay in the beam for a maximum of nearly two minutes at $5 \mathrm{~m}$ with a 30-degree cone. Any crystal rise (or fall) is seen as an oblique trace in the backscatter timeseries field, so that each streak in the echogram corresponds to a single crystal. An analysis was developed to quantify local vertical motion over the $270 \mathrm{~s}$ from scan to scan. Each acoustic profile was first scaled to remove depthattenuation of acoustic strength. Then the data were stepped through in time, breaking each profile into vertical segments. For each vertical segment, the next profile in time was searched for where this 
segment had the best match in terms of intensity distribution. This allowed synthesis of a distribution of rise speeds. Despite superficial appearances, the angled trajectories relate to the crystal rise speed and are unconnected to the tidal advection. Horizontal flow instead controls the persistence of individual reflectors as it is responsible for moving crystals in and out of the acoustic beam.

\subsection{Profiling instruments}

Water column temperature and salinity were recorded using a SBE19+ CTD profiler that was calibrated pre- and post-experiment resulting in an accuracy of $\sim 5 \mathrm{mK}$. Care was taken to avoid ice growth on the CTD sensors, and also to thermally equilibrate prior to profiling (Robinson et al., 2020). The example used here is a down-cast from an instrument that was held for one hour at $200 \mathrm{~m}$ prior to bringing up into the hole very briefly and then profiling downwards.

In addition to the CTD profiler, a Rockland VMP 250 microstructure profiler was deployed to quantify turbulent mixing by capturing fine and microstructure scale variability. This loose-tethered profiler falls at $\sim 0.65 \mathrm{~m} \mathrm{~s}^{-1}$, recording velocity shear and temperature at the microscale and fine-scale temperature and conductivity along with some other properties. The microscale shear enables estimates of energy dissipation rate $\varepsilon$ (Wolk et al., 2002) and has previously been successfully deployed beneath Antarctic fast ice (Robertson et al., 1995; Stevens et al., 2009; Fer et al., 2012). Eighty-one microstructure profiles were recorded over a three-day period (1-3 Nov. 2015).

\subsection{Moored instruments}

Three pairs of current meters (Aanderra RCM 11) and conductivity-temperature-pressure sensors (Seabird Electronics SBE 37), both sampling at two-minute intervals, were deployed on a suspended mooring located at $77^{\circ} 51.903^{\prime} \mathrm{S} 166^{\circ} 00.351^{\prime} \mathrm{E}, 200 \mathrm{~m}$ north east of the main sampling location. The instrument pairs were deployed at 32,82 and $374 \mathrm{~m}$ beneath the surface. In addition, ten SBE 56 temperature loggers sampling at $1 \mathrm{~Hz}$ were deployed at 5, 10, 15, 20, 43, 53, 141, 199, 257, $315 \mathrm{~m}$. All the upper instruments were affected by icing issues (Robinson et al., 2020) to varying extents and only used in specific instances here.

\section{Results}

\subsection{Background water column conditions}

Water column temperature structure showed that the ocean temperatures were mostly above the pressure-dependent freezing level (Figure 2). The exception to this was the upper $\sim 50 \mathrm{~m}$ which was always in situ supercooled, sometimes with a clear change in structure at the depth of transition to nonsupercooled. The upper layer temperature/salinity $\left(S_{p}=34.65 \mathrm{psu}, \theta_{0}=-1.94{ }^{\circ} \mathrm{C}\right.$ or for TEOS-10, $\mathrm{S}_{\mathrm{A}}=34.82 \mathrm{~g} \mathrm{Kg}^{-1}, \Theta_{0}=-1.94{ }^{\circ} \mathrm{C}$ ) indicates Ice Shelf Water (ISW) conditions. The potential temperature 
comes close to freezing again at $80 \mathrm{~m}$ but beneath this, even though temperatures remained below $\theta_{0}=-$ $1.91{ }^{\circ} \mathrm{C}$, the water was not in situ supercooled. The relatively homogeneous upper layer salinity (34.65 psu) gives away to a quasi-linear increase below $100 \mathrm{~m}$.

The deepest current meter provided the best quality current speed results (Figure 3a,b). The upper current meter did work for a few days at the beginning and was sufficient to show that the upper speeds were between 50 and $100 \%$ faster than the deep flows, at least in the conditions at the time. This is likely the result of the buoyantly forced ice shelf water plume. The experiment commenced near the end of spring tides followed by neap tide around DOY 297-299 and then the following spring tides peaked around DOY 304.5. The tidal speeds are clearly apparent with an amplitude of $0.1 \mathrm{~m} \mathrm{~s}^{-1}$. However, they are not the only advective process, as a period of flow near the start of the experiment showed speeds in excess of $0.1 \mathrm{~m} \mathrm{~s}^{-1}$ and consistently moving towards the north (i.e. away from the ice shelf). Temperature and salinity were consistent over the period but still responding to the tide at times.

\subsection{Ice crystals and backscatter}

The majority of the measured crystal dimensions ranged from $5 \mathrm{~mm}$ through to $200 \mathrm{~mm}$ (Figure 4). The average plan-view dimension in 2015 was $93 \mathrm{~mm}$ (with a slightly larger $101 \mathrm{~mm}$ equivalent measured the following year). Thicknesses were $2-10 \mathrm{~mm}$, with the thicker ones clearly multi-layered (thickness was not measured in the subsequent data set). The ice crystals (Figure 4a) were often larger than $100 \mathrm{~mm}$ in apparent scale (Figure 4c) and while these are found in the well-defined SIPL beneath the sea ice, it became clear that there was a constant supply of crystals from depth, some of which were already of large scale.

There appeared to be two types of behaviour from visual video observations (Figure 5). The first was seen at around $10 \mathrm{~m}$ depth platelet crystals were being advected horizontally but with some randomness to direction and not always with an obvious upwards component. The second type was seen in imagery from just beneath the ice $(\sim 1 \mathrm{~m})$ which showed a more ordered region of suspended crystals, especially at slack water. The smaller ones drifted slowly horizontally coherently while the larger individuals were occasionally and independently seen rising into the SIPL.

The $200 \mathrm{kHz}$ echosounder provided a new perspective on the presence and behaviour of these suspended crystals as various acoustic backscatter conditions were observed over the nine days of sampling (Figure 6). These conditions included large individual biological agents observed against a slowly varying background (Figure 6a) on occasionally with a more rapidly varying background (Figure 6b). It was also common to observe a varying intensity in the background field (Figure 6c), but individual target streaks would persist through the signal variation. The target strength was not a reliable separator however, as there would occasionally be strong scatterers that simply rose and entered the SIPL. Interpretation of video suggests these are relatively large crystals. 
The analysis of crystal rise speed (Figure 7) found only a moderate bias to upwards flows and quite small velocities (mostly less than $1 \mathrm{~cm} \mathrm{~s}^{-1}$ ). With the larger crystals being around $7 \mathrm{~cm}$ in diameter and rise speeds of the order of $1 \mathrm{~cm} \mathrm{~s}^{-1}$, this implies a Reynolds number $\operatorname{Re}=0.01 \times 0.07 / 10^{-6}=700$. Instability behind a buoyant disk commences well below this at $\operatorname{Re}=\sim 60$ (Natarajan and Acrivos, 1993). However, a significant proportion of crystal speeds are downwards i.e. against buoyancy (positive velocity as shown in Figure 6b). This suggests that the upper water column is some combination of (1) internal wave motion that is as likely to be downward as it is upwards, (2) isotropic shear-driven mixing and/or (3) convective instability whereby the crystals are entrained into drainage plumes from the SIPL.

The vertically integrated acoustic backscatter doesn't show any obvious consistent correlation with the velocity and scalar properties. There are some exceptions to this though. For example, near the end of day 298 (peak 2 in Figure 3) at which point we see shift from uni-directional flow through to a tidal oscillation and this comes at the end of a period of dropping temperatures (although only dropping by $30 \mathrm{mK}$ ) and increasing salinity. Simultaneously we observed the rise period to the highest backscatter (which is log-scale $\mathrm{db}$ ). There is another instance where speed peaks correspond to changes in temperature, salinity and backscatter (peak 5). Near the end of the experiment at peak 7 again a velocity peak coincided with a change in backscatter, flow direction and salinity suggesting an entirely new water mass was moving by. It is noteworthy that the 3-4-day trends are comparable between temperature and acoustic backscatter as the pre day 299 conditions give way to a decline in backscatter while temperatures rise steadily over days 299-302. After day 302 the trends in both temperature and backscatter remain flat. These periods also correspond to changes in the tidal structure with unidirectional flow prior to day 298 then transitioning (days 299-302) to steady back and forth tides (post day 301).

When considering the frequency structure (Figure 8), the timeseries are not long enough to enable analysis to extend much lower than the diurnal tidal frequencies. The current meter spectrum is dominated by the tide with almost one third of the spectrum reaching an apparent noise-floor. The temperature spectrum (from the sensor within the supercooled upper ocean) broadly conforms to three sections, the upper and lower of which both follow a $f^{-5 / 3}$ slope consistent with an isotropic turbulent cascade. However, this is interrupted with a band between 20-80 cpd (marker c in Figure 8 i.e. 20-70 min). The echo sounder spectrum can be broken into several components. Between the tidal frequency and $100 \mathrm{cpd}$ (marker a i.e. $15 \mathrm{~min}$ ) the slope is less than unity. Beyond this the slope is much steeper, with a local peak at $60 \mathrm{cpd}$ (marker b i.e. $24 \mathrm{~min}$ ). This could either indicate there is enhanced energy in this range, or that the vertical averaging serves to dampen higher frequencies. Considering a convective velocity scale of say $5 \mathrm{~mm} \mathrm{~s}^{-1}$ (as indicated by $\varepsilon$ ) cycling over a surface layer of $50 \mathrm{~m}$ suggests a turnover time of around 3 hours $(8 \mathrm{cpd})$. This suggests the variability we are seeing is happening relatively quickly compared to the mechanical operation of the upper layer. Conversely, the 

$9000 \mathrm{cpd}$. These sit well into the high frequency tail of the spectrum (Figure 8). Another scale of variability that will be apparent at least close to the surface is the SIPL underside has around a 2-5 $\mathrm{m}$ undulation which coupled with a $0.1 \mathrm{~m} \mathrm{~s}^{-1}$ implies a $20 \mathrm{~s}$ variation. This too falls to the right in the high frequency content.

\subsection{Boundary-layer turbulence}

The VMP profiles revealed mostly good quality turbulent spectra (Figure 9) allowing for reliable estimation of $\varepsilon$ which provides insight into the dynamics of the vertical structure of suspended crystals (Figure 10). The time-averaged temperature and salinity profiles (over around 48 hours) supported the structure from the CTD profile of a homogeneous water column. The averages revealed an apparent warm, salty layer in the $5 \mathrm{~m}$ just beneath the SIPL. Note this layer is not apparent in all individual realisations. The temperature effect on stability is almost passive in this temperature range and so does not compensate for the observed salinity increase and so the upper $15 \mathrm{~m}$, on-average, is weakly unstable. It is possible that the near-SIPL instability it is an effect of the ice hole, but the water in the hole itself is stabilised with much fresher water and it is not clear how rapid response sensors would register any false salinity readings. In addition, equivalent conditions have been observed just beneath the SIPL elsewhere (Robinson et al., 2014). A time-averaged profile of turbulent dissipation rate $\varepsilon$ (Figure 10b) is dominated by the higher values but generates a smooth profile, the bulk of which is comparable to a scaling argument for $\varepsilon$ based on the characteristic turbulence velocity scale $u *$ and the distance from the boundary ( $z$ ) so that $\varepsilon=u *^{3} /(K z)$, where $K$ is von Kármán's constant $\sim 0.41$. However, this fit works best beneath the upper layer (i.e. deeper than $10 \mathrm{~m}$ ).

\section{Discussion}

\subsection{Is there evidence of large pelagic crystals?}

The measured crystal sizes represent the large structural material of the SIPL. However, it is clear that large crystals can exist in suspension as we could see them visually and can be a source for the SIPL. Visual observation could not see the presumably more typical $<1 \mathrm{~mm}$ crystals (e.g. Frazer et al., 2020). It remains uncertain as to what proportion of the large crystals extracted from the SIPL underside had grown in situ vs directly deposited. Given that they were barely amalgamated (c.f. the "loose" platelets of Arndt et al., 2020) it seems possible that they are recent large arrivals. On the other hand, it seems implausible that such large crystals couple float upwards but do not generate a much higher rise velocity.

As Hoppmann et al. (2020) explains, the understanding of the initiation of crystal formation is not yet well established. Generally, active acoustic probing provides a useful tool to interpret suspended 
particle dynamics. Away from ice shelves it is usual to relate acoustic backscatter to a combination of individual motile biological targets and a background continuum signal. In the open or coastal ocean these usually relate to different species scales or suspended sediment. In such situations, fish and large zooplankton present as individual targets whilst the phytoplankton or sediment form a background continuum signal. The conditions in the present data suggest there is a high probability that the majority of our observed targets are pelagic platelet crystals and that the net upwards transport (Figure 7) suggests they form at depth and are not grown from surface-induced processes.

In the present sub-ice situation, the acoustic backscatter data falls into three categories - (1) large, bright individual backscatter, (ii) medium scale "less-bright" individual backscatter targets and (iii) a slowly varying background field. The Frazer et al. (2020) observations took place nearby (in a different year) and used four separate acoustic frequencies including one matching the present EK60. The nature of the ISW outflow is not consistent from year to year. In the present context they primarily captured the background field, as the majority of their crystals were estimated to be around $1 \mathrm{~mm}$ in scale and any large crystals would have been removed by the processing. Video observations and target behaviour support the contention that the majority of rare very "bright" individual targets were large fauna - ranging from fish, fish schools through to seals. However, it was far more common to observe a hybrid of the $2^{\text {nd }}$ and $3^{\text {rd }}$ conditions whereby the sampled field consisted of many less bright but still clearly individual signals against a coherent background field. The present situation is downstream of the Ross Ice Shelf cavity within which residence times in zero light likely to be in the range of 1-5 years (Reddy et al., 2010; Stevens et al., 2020). This reinforces the contention that the targets and continuum are ice related rather than suspended biological or sediment.

Here we refer to the large, mature crystals at depth as pelagic crystals to distinguish them from crystals already integrated and growing in the SIPL. Laboratory and numerical work demonstrate that buoyant disks rotate so that their flat face is roughly horizontal although in some circumstances it is possible for an oblique equilibrium to exist which might be the cause of some of the horizontal motion observed here (Fabre et al., 2012). Furthermore, the behaviour of rising disks can be connected back to the initial conditions, suggesting attention be paid to the spontaneous growth from a very small nucleus (Daly 1984; Tchoufag et al., 2014). Assuming the freshwater results of McFarlane et al. (2014) provide a minimum rise velocity (i.e. here we expect greater buoyancy different between crystal and saltwater) then their results for non-vertical disks suggests $\mathrm{w}_{\mathrm{c}}=\alpha \mathrm{d}$ (with $\alpha=1 \mathrm{~s}^{-1}$, at least for diameter $\mathrm{d}<6 \mathrm{~mm}$, where the one-to-one equivalence has no dynamic significance). Rees Jones and Wells (2018) use one of the faster rise rates from the same set of results which is applicable to smaller crystal sizes (e.g. none of which conforms to the drag based estimates described in Daly, 1984) whereas Matsumura and Oshima (2015) use a fixed rise rate of $1 \mathrm{~mm} \mathrm{~s}^{-1}$, again for small crystals.

Production of crystals at depth and its subsequent integration into sea ice is a key step in the formation of the SIPL, at least at this location (Hoppmann et al., 2015; Hunkeler et al., 2015). This has 
several implications, the most important being an alternate pathway for platelet arrival and structuring of the SIPL. If they arrive essentially mature at the $\sim 5 \mathrm{~cm}$ scale, this is very different to arriving at the 1 mm scale and then growing (Dempsey et al., 2010) and the categories of backscatter described earlier suggest both happen. The issue of orientation suggests that the arrival velocity will be slower than if they were to rise in some other orientation with a reduced drag profile. Thus, there may be a correlation between rise speed and packing in the SIPL. Potentially this alignment relates to the large-scale variability seen in Figure $6 \mathrm{c}$ whereby large parts of the domain change backscatter but individual scatterers are clearly seen through the transition. In other words, horizontal flow is slow, yet the scattering still changes as crystals re-orientate themselves within the sensing volume.

The influence of pelagic crystals can be represented in larger-scale models such as Kim et al. (2006) and Roach et al. (2018). However, it will require some local-scale mechanics. For example, Dempsey et al. (2010) and Wongpan et al. (2015) simulate this aggregation by injecting a continuous flux of crystals from the ocean at the same time as recording (i) the rate at which the sea ice incorporation front moves downward and (ii) below this front but still within the SIPL, crystals continue to grow. In their approach, they maintain different size classes for the deposited systems as opposed to those floating up from below. This implies that there is an ability for the rising crystals to fill in the interstices of the SIPL, reducing the void fraction. This is a point made by Dempsey et al. (2010) who quantified the flux rate of $4 \mathrm{~mm}$ diameter platelets required to grow the observed sea ice to be of order $10^{6}$ crystals $\mathrm{m}^{-2} \mathrm{~d}^{-1}$.

The pelagic growth to the crystals also means that the brine rejection will happen essentially within the upper ocean layer as well at the sea ice underside. This affects the upper layer turbulence and entrainment. In turn, this influences the persistence and fate of the ISW plume. This shifts the buoyancy flux inherent in the energy conversion from a boundary process to what is effectively an "internal buoyancy source".

\subsection{Crystal behaviour in the turbulent under-ice boundary-layer}

It is useful to compare vertical rise rate of crystals $w_{c}$ with turbulent mixing in the water column. The present profiler-resolved dissipation rates are comparable with Fer and Widell's (2007) data from beneath Arctic sea ice in a fjord. However, while both studies observed turbulent energy dissipation rates in the range $\varepsilon=10^{-7}$ to $10^{-6} \mathrm{~W} \mathrm{~kg}^{-1}$, their results were from a faster-moving water column. It would appear the rougher ice underside here increases the turbulence to provide apparent matching conditions. In the upper water column (5-10 m), the dissipation rate is an order of magnitude, or more, greater than the value expected if we match the deeper $\varepsilon$. One hypothesis is that we are seeing brine rejection and associated enhanced turbulence. Regardless, the $\varepsilon$ provides a dynamic context for considering how the pelagic platelet crystals behave. The $\mathrm{u} *$ is a combination of convection-induced turbulence and draginduced stirring. Observations of boundary-layers beneath platelet ice have suggested that the drag 
coefficient is a factor of 6-30 times larger than might be expected for a smooth, melting ice surface (Robinson et al., 2017). This reinforces the apparent paradox that melting ice (the shelf basal underside) produces re-freezing that then affects how the entire system circulates. A key knowledge gap highlighted then is the under-shelf mixing in the basal melt layer. This will influence not only the sub-shelf re-freezing but the amount of supercooled water being ejected into the sea ice system.

Fer et al. (2012) observed crystal-laden water emerge from beneath the Brunt Ice Shelf into an ocean with $3 \mathrm{~m}$ thick fast ice. They did not observe an unstable temperature-salinity structure, but this may be due to sampling differences when working from a ship and through a larger hole. They did observe an increase in $\varepsilon$ when supercooling conditions occurred, reaching around $5 \times 10^{-7} \mathrm{~W} \mathrm{~kg}^{-1}$ when temperatures fell to $30 \mathrm{mK}$ below surface freezing. They attributed the increase in turbulence to being due to crystal formation and rise. Conditions were comparable to that observed here with flow speeds reaching $0.15 \mathrm{~m} \mathrm{~s}^{-1}$. They too observed ice-related increased in $75 \mathrm{kHz}$ ADCP backscatter although the resolution is much coarser than possible with dedicated echo sounders.

Mean stratification in the present $2015 \mathrm{~K} 131$ work is very weak in the upper $50 \mathrm{~m}$ so diffusion in this layer (thickness $h$ ) is estimated as $K_{v} \approx u * h$ where $\mathrm{u}^{*}$ is derived from the observed dissipation rate by assuming $\varepsilon=u * / h$. Given the $K_{v}$ model of redistribution of material in the vertical, the relative influence of sinking (or rising) compared to the turbulent influence may be gauged using a turbulent particle Péclet Number (O’Brien et al., 2003) $P e_{t}=w_{d} d u_{*}$. which compares the rise speed to turbulence intensity (c.f. Gopalan et al., 2008 who produced similar scaling for oil droplets but different to Daly 1984 who used a molecular diffusion equivalent). Large $P e_{t}$ implies particle buoyancy dominates over turbulence so that in the absence of growth, $P e_{t}>>1$ indicates that settlement outstrips the redistribution through turbulence. On the other hand, $P e_{t}<1$ describes where the crystals are continually being redistributed throughout the water column regardless of their intrinsic rise speed (c.f. Rees Jones and Wells 2018 frazil "explosion”). Dissipation rates in the range $\varepsilon=10^{-7}$ to $10^{-6} \mathrm{~W} \mathrm{~kg}^{-1}$ over a vertical scale of $10 \mathrm{~m}$ results in an estimate of $\mathrm{u} * \approx 0.01-0.02 \mathrm{~m} \mathrm{~s}^{-1}$ which is larger than both the average and maximum observed rise rates and suggests a small apparent $P e_{t}$. Placing the combined upper ocean turbulence and crystal size data in this $P e_{t}$ context (Figure 11), it appears that the average crystals and turbulence conditions result in a situation where the rise speed should more than exceed turbulence motions. However, considering the regime of smaller crystals in more turbulent conditions, then the $\varepsilon$ would be comparable. Notably, all of the continuum crystals observed by Frazer et al. (2020) fall to the far left (small crystal diameter) of the $P e_{t}$ domain.

The apparent bi-directional variability in vertical motion (Figure 7) implies wave-type motion. However, the density structure gives no indication of stratification in the upper 30-50 m that would support internal waves. It is possible that slow horizontal advection of convective processes moving down and upwelling flows past the observation location might also be a factor influencing the measured quantities. 


\subsection{Does sediment play a role in the mechanics?}

While suspended sediment has been implicated in atmospheric ice formation (Kulkarni et al., 2014), it has not been identified as a nucleation point for marine ice crystal growth. Daly (1984) indicated that the thermodynamics precludes sediment playing a lead role in nucleation. However, there may be other pathways i.e. through aiding aggregation of ice crystals that can support nucleation. Previous observations in the region (Robinson et al., 2017) had not provided strong evidence that suspended sediment plays an important role in the SIPL in the region, so we did not have equipment specifically designed for such conditions. Sediment can potentially enter the water column through several pathways. First it might be held within the ice sheet underside as it leaves the coast at the grounding line, at which point it melts out and enters the basal boundary layer. Second, in some circumstances it might lift off from the seabed as part of an anchor ice process. Finally, sediment could be transported north by wind. This aeolian pathway deposits material on the sea ice surface at which point it would then have to find its way through the sea ice via brine channels. Atkins and Dunbar (2009) identified wind-blown transport in the region and leading to enhanced sediment concentrations in the sea ice. Here the wind-blown sediment is partly marine in origin and moved upwards through surface ablation/bottom accretion processes (Figure 12a).

The coincidence of a substantial sediment load suggests that, in this location at least, this might enhance crystal formation. However, a ready source of sediment is potentially a rare phenomenon at the continent-wide shelf edge suggesting that it is not a major controller of crystal production. It remains highly likely at grounding line zones where a confluence of ice shelf water outflow, glacially-driven sediment supply, tidal and subglacial resuspension and supercooling-induced re-freezing all likely combine. Furthermore, substantial platelet ice layers exist in many ice shelf influenced locations where there is no obvious sediment source (Langhorne et al., 2015; Hoppmann et al., 2020). The intriguing speculation that follows from this is - what role might sediment play in crystal nucleation near ice shelf grounding-lines and would we be able to tell if this influences marine ice formation (e.g. Fricker et al., 2001)?

\subsection{What are the large-scale implications of flow-crystal interaction?}

Local datasets such as the present experiment need to be placed into regional and continent-wide perspectives. There is a clear regional bias due to the majority of data coming from only a few field locations (Hoppmann et al., 2020). Debenham's comment about the region being the "strangest on the planet" suggests there may be some unique features that can't be generalised. While he wrote this in 1965 when Antarctica was still very under-surveyed it is not clear that there are many locations quite like the McMurdo Ice Shelf. At the regional Southern McMurdo Sound scale, Grima et al. (2016) and Brett et al. (2020) surveyed the area of the present study using remote sensing instruments that can detect platelet-influenced sea ice. Their surveys supported the conclusions drawn from the in-situ 

the McMurdo/Ross ice shelf system's western limit. The Langhorne et al. (2015) spatial distribution of SIPL in McMurdo Sound shows a tongue of thicker SIPL extending $50 \mathrm{~km}$ northward from the dirty ice region where the present 2015 results were collected. More recent survey work of Brett et al. (2020) shows a striking similarity between SIPL and the location of the Dirty Ice. However, this also corresponds to where one would expect basal cavity outflow so supply of ISW is available (Hughes et al., 2014). Following this water north, a number of studies have concluded that the ice shelf water from the Ross/McMurdo system persists for a hundred or more km northward (Hughes et al., 2014; Robinson et al., 2014).

Richter et al. (2020) state that ice shelf-sea ice-ocean connections remain the major outstanding challenge in models operating at the continental and global scale. Injection of the range of processes described here into modelling approaches that typically resolve scales around $2 \mathrm{~km}$ will be a challenge. A starting point might be the role present large platelets play in the McMurdo Sound polynya formation (Dai et al., 2020). Polynya processes in particular become critical as they represent spatially-constrained phenomena driven by short high energy wind events but pre-conditioned by ice shelf water, that then drive formation of new sea ice. It is the by-product of this sequence that generates high salinity shelf water that ultimately has a global thermohaline impact. Modelling of such processes thus may potentially need to better account for the nature of ice shelf water plumes.

The topic is clearly still in a discovery phase with many fundamental questions remaining unanswered. This work suggests research themes for understanding sea ice formation near ice shelves should focus on the role of convection driven by SIPL crystal growth in modifying the turbulence in the upper water column and the feedbacks to the turbulence. In addition, the possible links between availability of nucleating material, crystal production and fate need to be examined, especially as to how this might support the formation of large, suspended ice crystals.

Acknowledgements. We would like to acknowledge Professor Pat Langhorne for her leadership on the wider topic. Tim Haskell is thanked for his development of the K131 infrastructure program. We are grateful to Inga Smith, Pat Wongpan, Cecilia Bitz, Greg Leonard and Andrew Pauling for their assistance and insight. Antarctica New Zealand provided field support. Funding was provided by the Royal Society of New Zealand Marsden Fund, NIWA Strategic Science Investment Funding, N.Z. Antarctic Research Institute, the Deep South National Science Challenge, and the New Zealand Ministry of Business, Innovation and Employment through the Antarctic Science Platform (ANTA1801).

Data availability: data will be made available through an open repository. 
Author contribution: CS conceived the experiment, conducted the majority of the sampling and analysis and led the writing. NR contributed to the experiment design and writing, GO'C produced the crystal data and BG collected the timeseries data, and developed the sounder sampling approach.

Competing interests: The authors have no conflicting interests.

Arndt, S., Hoppmann, M., Schmithüsen, H., Fraser, A. D., and Nicolaus, M.: Seasonal and interannual variability of landfast sea ice in Atka Bay, Weddell Sea, Antarctica, To appear in The Cryosphere, https://doi.org/10.5194/tc-2019-293, 2020.

Atkins, C.B. and Dunbar, G.B.: Aeolian sediment flux from sea ice into Southern McMurdo Sound,

Brett, G.M., Irvin, A., Rack, W., Haas, C., Langhorne, P.J. and Leonard, G.H.: Variability in the Distribution of Fast Ice and the Sub-ice Platelet Layer Near McMurdo Ice Shelf. Journal of Geophysical Research: Oceans, 125(3), p.e2019JC015678, 2020.

Campbell, I.B. and Claridge, G.G.C.: Thermokarst landforms in the Transantarctic Mountains region of Antarctica. In Proceedings of the Eighth International Conference on Permafrost (pp. 21-25). Lisse, The Netherlands: Balkema, 2003.

Dai, L., Xie, H., Ackley, S.F. and Mestas-Nuñez, A.M.: Ice Production in Ross Ice Shelf Polynyas during 2017-2018 from Sentinel-1 SAR Images. Remote Sensing, 12(9), p.1484, 2020.

Daly, S.F.: Frazil ice dynamics (No. CRREL-MONO-84-1). Cold Regions Research and Engineering Lab., Hanover NH. https://apps.dtic.mil/dtic/tr/fulltext/u2/a142037.pdf, 1984.

Debenham, F:. The genesis of the McMurdo ice shelf, Antarctica. Journal of Glaciology, 5(42), pp.829$832,1965$.

Dempsey, D.E., Langhorne, P.J., Robinson, N.J., Williams, M.J.M., Haskell, T.G. and Frew, R.D.: Observation and modeling of platelet ice fabric in McMurdo Sound, Antarctica. Journal of Geophysical Research: Oceans, 115(C1). https://doi.org/10.1029/2008JC005264, 2010.

Fabre, D., Tchoufag, J. and Magnaudet, J.: The steady oblique path of buoyancy-driven disks and spheres. Journal of Fluid Mechanics, 707, pp.24-36. https://doi.org/10.1017/jfm.2012.231, 2012.

Fer, I., Makinson K., and Nicholls, K.: Observations of thermohaline convection adjacent to Brunt Ice Shelf. J. Phys. Oceanogr., 42:502-508. doi: 10.1175/JPO-D-11-0211.1, 2012.

Fer, I. and Widell, K.: Early spring turbulent mixing in an ice-covered Arctic fjord during transition to melting. Continental Shelf Research, 27(15), pp.1980-1999, 2007.

Frazer E.K., Langhorne P.J., Leonard G.H., Robinson N.J., Schumayer D.: Observations of the size distribution of frazil ice in an Ice Shelf Water plume, in review, 2020. 
Fricker, H. A., Popov, S., Allison, I., and Young, N.: Distribution of marine ice beneath the Amery Ice Shelf. Geophysical Research Letters, 28(11), 2241-2244, 2001.

Gopalan, B., Malkiel, E. and Katz, J.: Experimental investigation of turbulent diffusion of slightly buoyant droplets in locally isotropic turbulence. Physics of Fluids, 20(9), p.095102, 2008.

Grima, C., Greenbaum, J.S., Lopez Garcia, E.J., Soderlund, K.M., Rosales, A., Blankenship, D.D. and Young, D.A.: Radar detection of the brine extent at McMurdo Ice Shelf, Antarctica, and its control by snow accumulation. Geophysical Research Letters, 43(13), pp.7011-7018, 2016.

Hewitt, I.J.: Subglacial Plumes. Annual Review of Fluid Mechanics, 52, pp.145-169, 2020.

Holland, P.R., Feltham D.L., and Jenkins A.: Ice Shelf Water plume flow beneath Filchner-Ronne Ice Shelf, Antarctica, J. Geophys. Res., 112, C05044, doi:10.1029/2006JC003915, 2007.

Hoppmann, M., Nicolaus, M., Paul, S., Hunkeler, P. A., Heinemann, G., Willmes, S., ... \& Gerdes, R.: Ice platelets below Weddell Sea landfast sea ice. Annals of Glaciology, 56(69), 175, 2015.

Hoppmann, M., Richter, M.E., Smith, I.J., Jendersie, S., Langhorne, P.J., Thomas, D.N. and Dieckmann, G: Platelet ice, the Southern Ocean's hidden ice: a review. Annals of Glaciology, 62(82), 2020.

Hughes, K.G., Langhorne P.J., Leonard G.H., and Stevens, CL.: Extension of an Ice Shelf Water plume model beneath sea ice with application in McMurdo Sound, Antarctica, J. Geophys. Res. Oceans, 119, doi:10.1002/2013JC009411, 2014.

Hunkeler, P., Hendricks, S., Hoppmann, M., Paul, S. and Gerdes, R.: Towards an estimation of sub-seaice platelet-layer volume with multi-frequency electromagnetic induction sounding, Annals of Glaciology, 56 (69), pp. 137-146. doi: 10.3189/2015AoG69A705, 2015.

Jenkins, A. and Bombosch, A.: Modeling the effects of frazil ice crystals on the dynamics and thermodynamics of ice shelf water plumes. Journal of Geophysical Research: Oceans, 100(C4), pp.6967-6981, 1995.

Jordan, J. R., Kimura S., Holland P. R., Jenkins A., and Piggott M. D.: On the conditional frazil ice instability in seawater, J. Phys. Oceanogr., 45, 1121-1138, doi:10.1175/JPO-D-14-0159.1, 2015.

Kim, J.G., Hunke, E.C., and Lipscomb, W.H.: Sensitivity analysis and parameter tuning scheme for global sea-ice modeling. Ocean Modelling, 14(1), 61-80, 2006.

Kulkarni G, Sanders C, Zhang K, Liu X, and Zhao C.: Ice nucleation of bare and sulfuric acid coated mineral dust particles and implication for cloud properties. Journal of Geophysical Research: Atmospheres 119:9993-10,011. DOI:10.1002/2014JD021567, 2014.

Kusahara, K.: Interannual-to-Multidecadal Responses of Antarctic Ice Shelf-Ocean Interaction and Coastal Water Masses during the Twentieth Century and the Early Twenty-First Century to Dynamic and Thermodynamic Forcing. Journal of Climate, 33(12), pp.4941-4973, 2020.

Langhorne, P. J. and Hughes, K. G. and Gough, A. J. and Smith, I. J. and Williams, M. J. M. and Robinson, N. J. and Stevens, C. L. and Rack, W. and Price, D. and Leonard, G. H. and 

distribution of platelet ice around coastal Antarctica. Geophys. Res. Letters, 42(13), 5442-5451, 10.1002/2015GL064508 2015.

Leonard, G.H., Purdie, C.R., Langhorne, P.J., Haskell, T.G., Williams, M.J.M., and Frew, R.D.: Observations of platelet ice growth and oceanographic conditions during the winter of 2003 in McMurdo Sound, Antarctica, J. Geophys. Res., 111, C04012, doi:10.1029/2005JC002952, 2006.

Ludescher, J., Yuan, N. and Bunde, A.: Detecting the statistical significance of the trends in the Antarctic sea ice extent: an indication for a turning point. Climate Dynamics, 53(1-2), pp.237$244,2019$.

MacAyeal, D.R.: Evolution of tidally triggered meltwater plumes below ice shelves. Oceanology of the Antarctic continental shelf, 43, pp.133-143, 1985.

Mahoney, A. R., Gough, A. J., Langhorne, P. J., Robinson, N. J., Stevens, C. L., Williams, M. M. J., and Haskell, T. G.: The seasonal appearance of ice shelf water in coastal Antarctica and its effect on sea ice growth, J. Geophys. Res., 116, C11032, doi:10.1029/2011JC007060. 2011.

Matsumura, Y. and Ohshima, K.I.: Lagrangian modelling of frazil ice in the ocean. Annals of Glaciology, 56(69), pp.373-382, 2015.

McFarlane, V., Loewen, M. and Hicks, F.: Laboratory measurements of the rise velocity of frazil ice particles. Cold Regions Science and Technology, 106, pp.120-130, 2014.

McPhee MG; Stevens CL Smith IJ; Robinson NJ: Platelet growth in supercooled water limited by ocean heat transfer, Ocean Sciences. doi:10.5194/osd-12-2807-2015, 2016.

Moorman, R., Morrison, A.K. and McC. Hogg, A.: Thermal responses to Antarctic ice shelf melt in an eddy-rich global ocean-sea ice model. Journal of Climate, 33(15), pp.6599-6620, 2020.

Natarajan, R., and Acrivos, A.: The instability of the steady flow past spheres and disks. Journal of Fluid Mechanics, 254, 323-344, 1993.

O'Brien, K.R., Ivey, G.N., Hamilton, D.P., Waite, A.M. and Visser, P.M.: Simple mixing criteria for the growth of negatively buoyant phytoplankton. Limnology and Oceanography, 48(3), pp.1326$1337,2003$.

Penrose J.D., Conde M. and Pauly T.J.: Acoustic detection of ice crystals in Antarctic waters. J. Geophys. Res., 99(C6), 12 573-12 580 (doi: 10.1029/93JC03507), 1994.

Reddy, T.E., Holland, D.M. and Arrigo, K.R.: Ross ice shelf cavity circulation, residence time, and melting: Results from a model of oceanic chlorofluorocarbons. Continental Shelf Research, 30(7), pp.733-742, 2010.

Rees Jones, D. W. and Wells, A. J.: Frazil-ice growth rate and dynamics in mixed layers and sub-iceshelf plumes, The Cryosphere, 12, 25-38, https://doi.org/10.5194/tc-12-25-2018, 2018. 
Richter, O., Gwyther, D. E., Galton-Fenzi, B. K., and Naughten, K. A.: The Whole Antarctic Ocean Model (WAOM v1.0): Development and Evaluation, Geosci. Model Dev. Discuss., https://doi.org/10.5194/gmd-2020-164, in review, 2020.

Rignot, E., Jacobs, S., Mouginot, J., and Scheuchl, B.: Ice-shelf melting around Antarctica. Science, 341(6143), 266-270, 2013.

Roach, L.A., Dean, S.M. and Renwick, J.A.: Consistent biases in Antarctic sea ice concentration simulated by climate models. The Cryosphere, 12, 365-383, https://doi.org/10.5194/tc-12-3652018, 2018.

Robertson, R., Padman, L. and Levine, M.D.: Fine structure, microstructure, and vertical mixing processes in the upper ocean in the western Weddell Sea. Journal of Geophysical Research: Oceans, 100(C9), pp.18517-18535, 1995.

Robinson NJ, Stevens C.L., Stewart C.L., Williams M.J.M, Grant, B.S.: Oceanographic observations in supercooled water: Protocols for mitigation of measurement errors in profiling and moored experiments, Cold Regions Science and Technology. 170, p.102954 https://doi.org/10.1016/j.coldregions.2019.102954 2020.

Robinson, N. J., Williams, M. J. M., Stevens, C. L., Langhorne, P. J., and Haskell, T. G.: Evolution of a supercooled Ice Shelf Water plume with an actively growing subice platelet matrix, J. Geophys. Res. Oceans, 119, 3425- 3446, doi:10.1002/2013JC009399, 2014.

Robinson N.J., Stevens C.L., McPhee M.G.: Observations of amplified roughness from crystal accretion in the sub-ice ocean boundary layer, Geophysical Res. Lett. DOI: 10.1002/2016GL071491, 2017.

Smedsrud, L.H. and Jenkins, A.: Frazil ice formation in an ice shelf water plume. Journal of Geophysical Research: Oceans, 109(C3), 2004.

Smith I.J., P.J. Langhorne, T.G. Haskell, H.J. Trodahl, R.D. Frew and R.M. Vennell: Platelet ice and the land-fast sea ice of McMurdo Sound, Antarctica. Annals of Glaciology 33: 21-27, 2001.

Stevens, C., Hulbe, C., Brewer, M., Stewart, C., Robinson, N., Ohneiser, C. and Jendersie, S.: Ocean mixing and heat transport processes observed under the Ross Ice Shelf control its basal melting. Proceedings of the National Academy of Sciences, 117(29), pp.16799-16804. https://doi.org/10.1073/pnas.1910760117, 2020.

Stevens C.L., Langhorne P.J., Robinson N.J.: K131 Antarctic sea ice science: A case study of infrastructure, strategies, and skills, New Zealand Science Review, 74, 66-72, 2018.

Stevens, C. L., N.J. Robinson, M.J.M. Williams and T.G. Haskell: Observations of turbulence beneath sea ice in southern McMurdo Sound, Antarctica, Ocean Sci., 5, 435-445, 2009.

Tchoufag, J., Fabre, D. and Magnaudet, J.: Global linear stability analysis of the wake and path of buoyancy-driven disks and thin cylinders. Journal of Fluid Mechanics, 740, pp.278-311, 2014. 
https://doi.org/10.5194/tc-2020-249

Preprint. Discussion started: 12 October 2020

(C) Author(s) 2020. CC BY 4.0 License.

cC) (i)

Wolk, F., Yamazaki, H., Seuront, L. and Lueck, R.G.: A new free-fall profiler for measuring biophysical microstructure. Journal of Atmospheric and Oceanic Technology, 19(5), pp.780793, 2002.

Wongpan, P., Langhorne, P.J., Dempsey, D.E., Hahn-Woernle, L. and Sun, Z.: Simulation of the crystal growth of platelet sea ice with diffusive heat and mass transfer. Annals of Glaciology, 56(69), pp.127-136. 2015.

595 
Figures
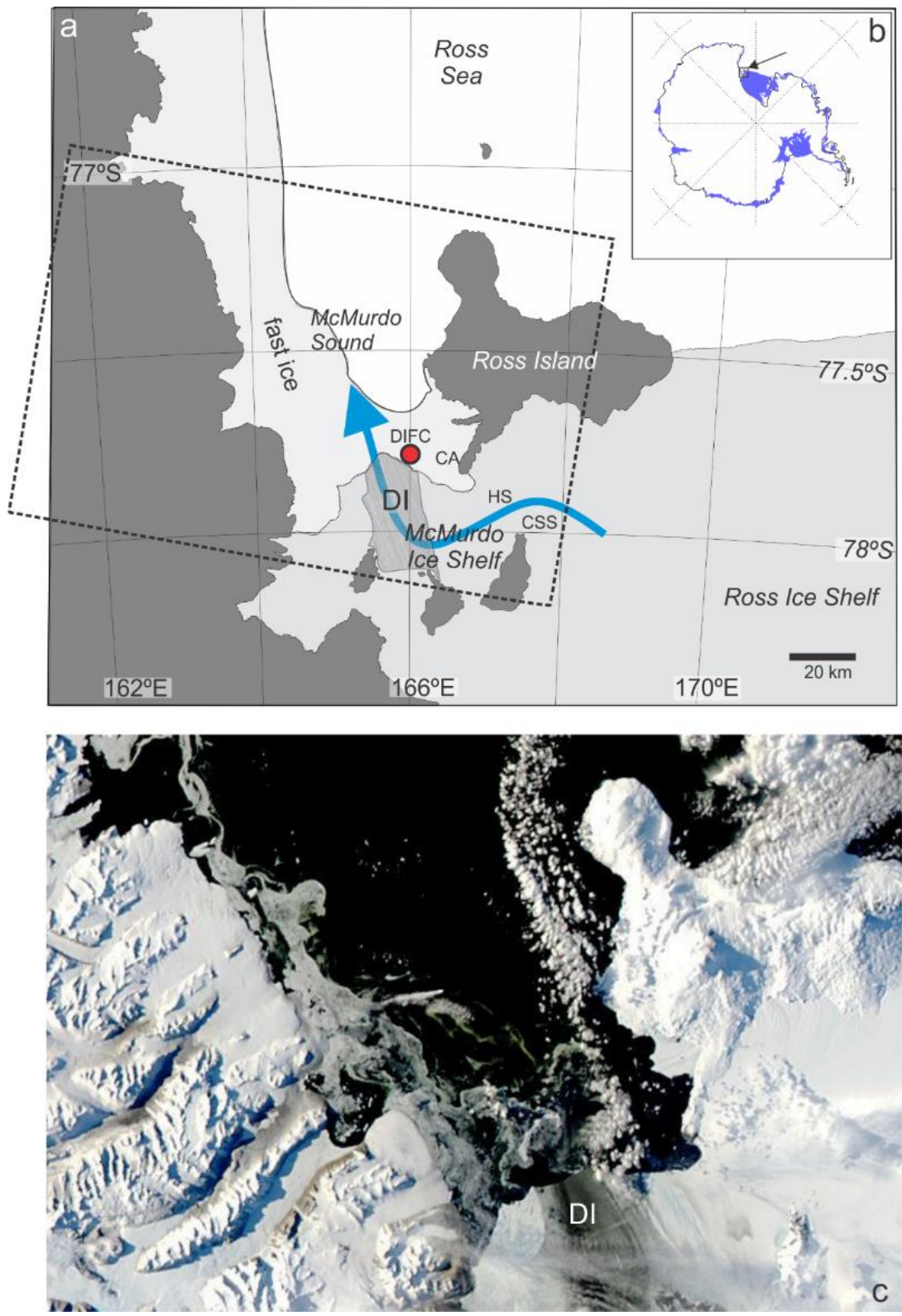

Figure 1 Location details including (a) McMurdo Sound as an exit point for the Ross Ice Shelf cavity (showing DIFC=Dirty Ice Field Camp, HS=Haskell Strait, CSS=Cape Spencer-Smith, $\mathrm{CA}=$ Cape Armitage and the Dirty Ice=DI). The arrow shows the path of ice shelf water following the complementary perspectives of Robinson et al. (2014) and Brett et al. (2020). (b) Antarctica and ice shelf margin shown in blue with McMurdo Sound sub-region identified. (c) Modis imagery from 2016 day 057 showing the dark smudge of the "dirty ice" (DI). 


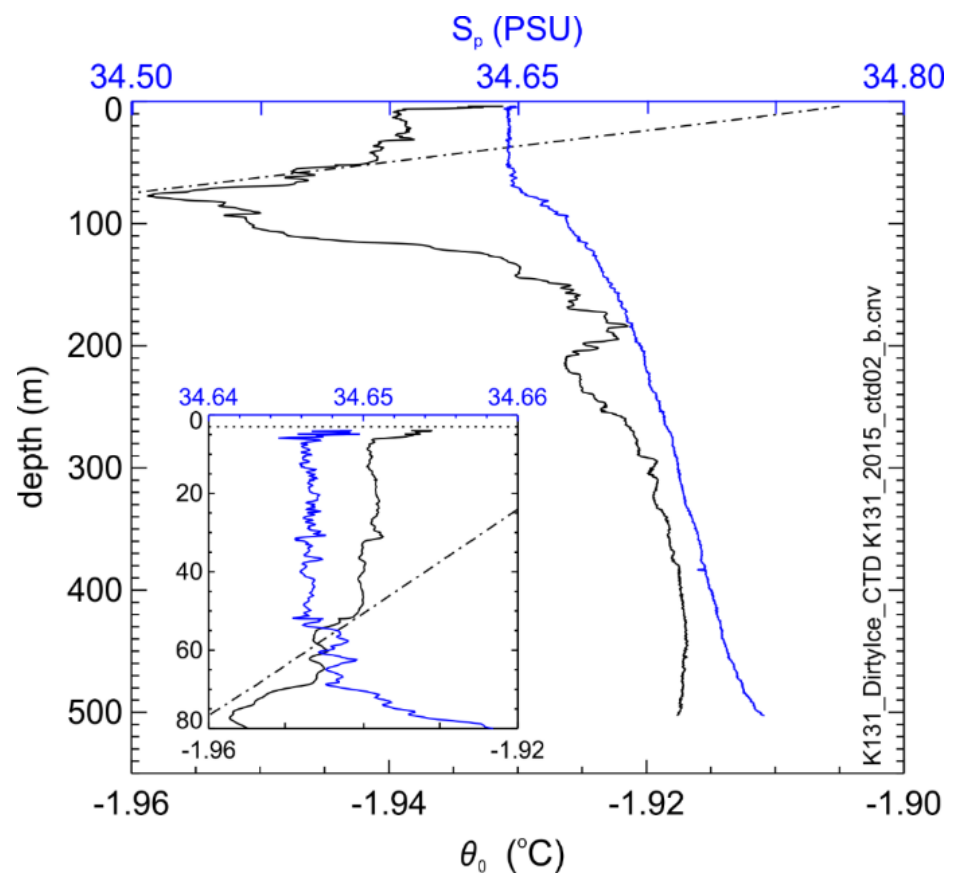

Figure 2 Example vertical profiles of temperature and salinity from the CTD, along with the in situ freezing temperature. The inset shows an expanded view of the upper $80 \mathrm{~m}$. This profile was from 0100 UTC on the $27^{\text {th }}$ of November 2015. 

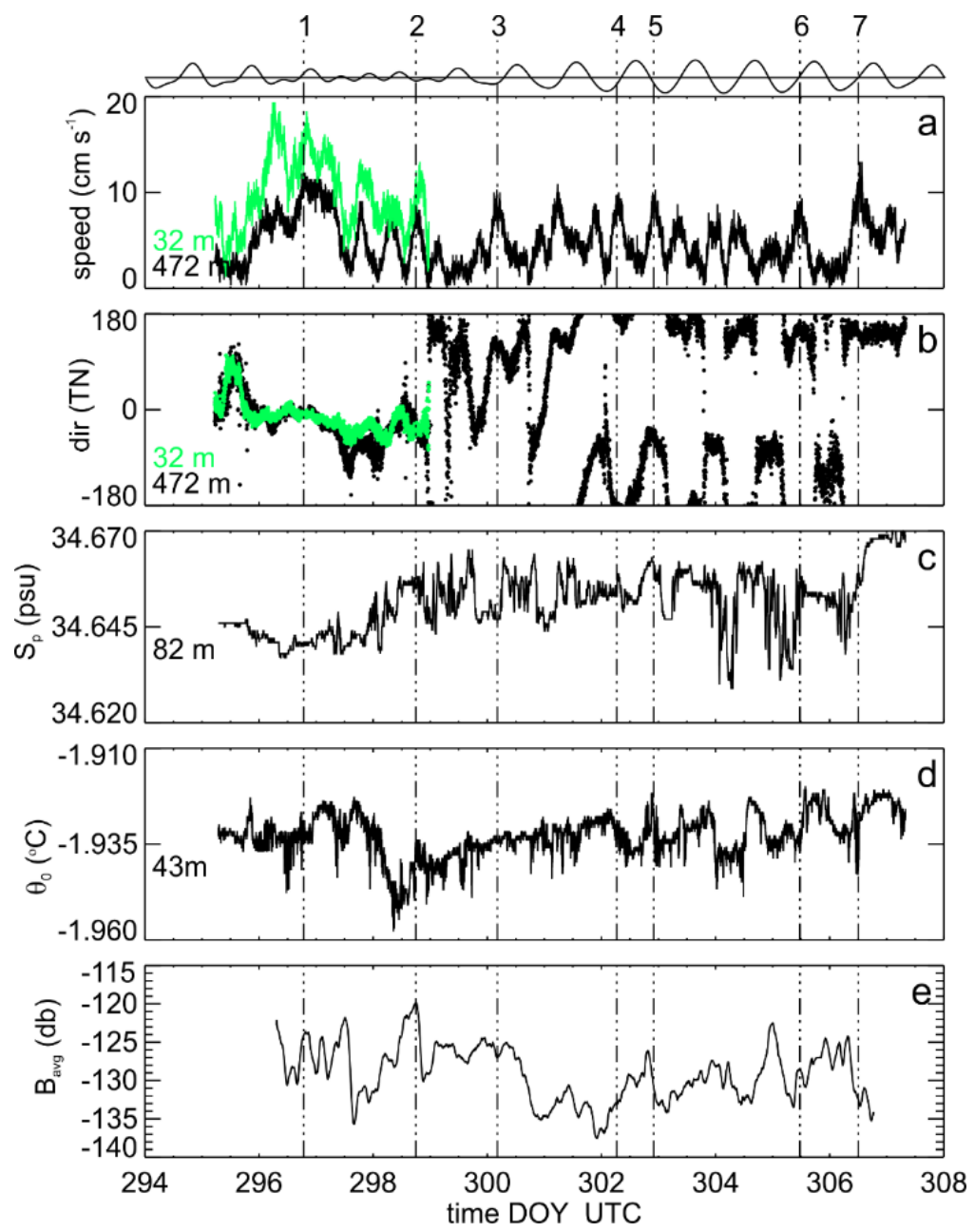

Figure 3 Moored instrument data showing timeseries of (a) current meter speed at $472 \mathrm{~m}$, (b) flow direction (towards) at $472 \mathrm{~m}$, (c) salinity at $82 \mathrm{~m}$, (d) potential temperature at $43 \mathrm{~m}$ and (e) vertically-averaged acoustic backscatter. Panels (a) and (b) include a short segment from the upper current meter $(32 \mathrm{~m})$ prior to ice-up. Selected peaks in speed are highlighted in all panels using vertical dashed lines and the modelled tidal height is traced above the top panel. 

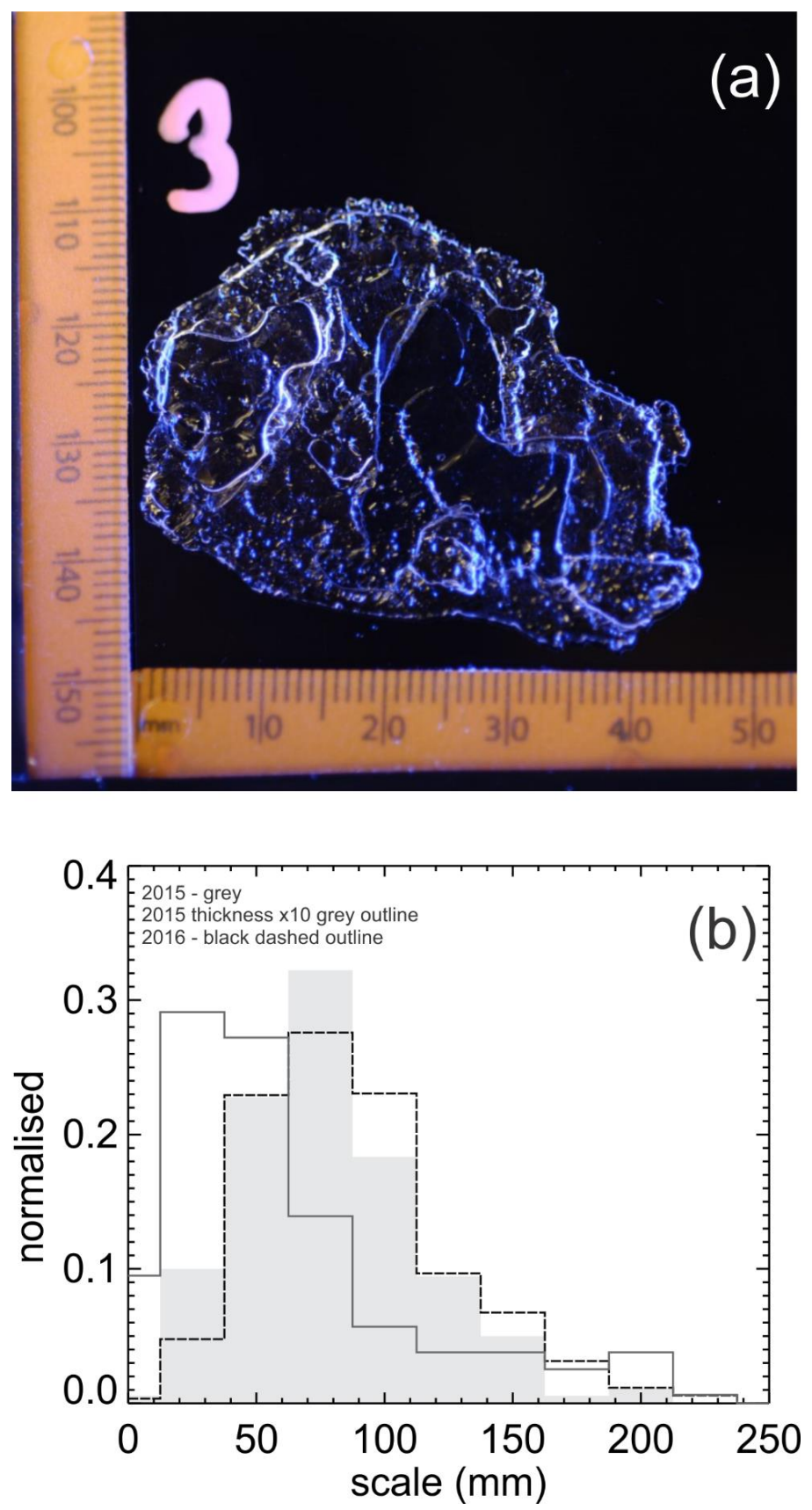

620 Figure 4 Crystal details including (a) an image of an example platelet (ruler in mm). (b) Scale distributions for 2015 (180 platelets) vector average of plan-view dimensions and the crystal thickness (scaled larger by a factor of 10) and 2016 (864 platelets, vector average of plan view dimensions). 


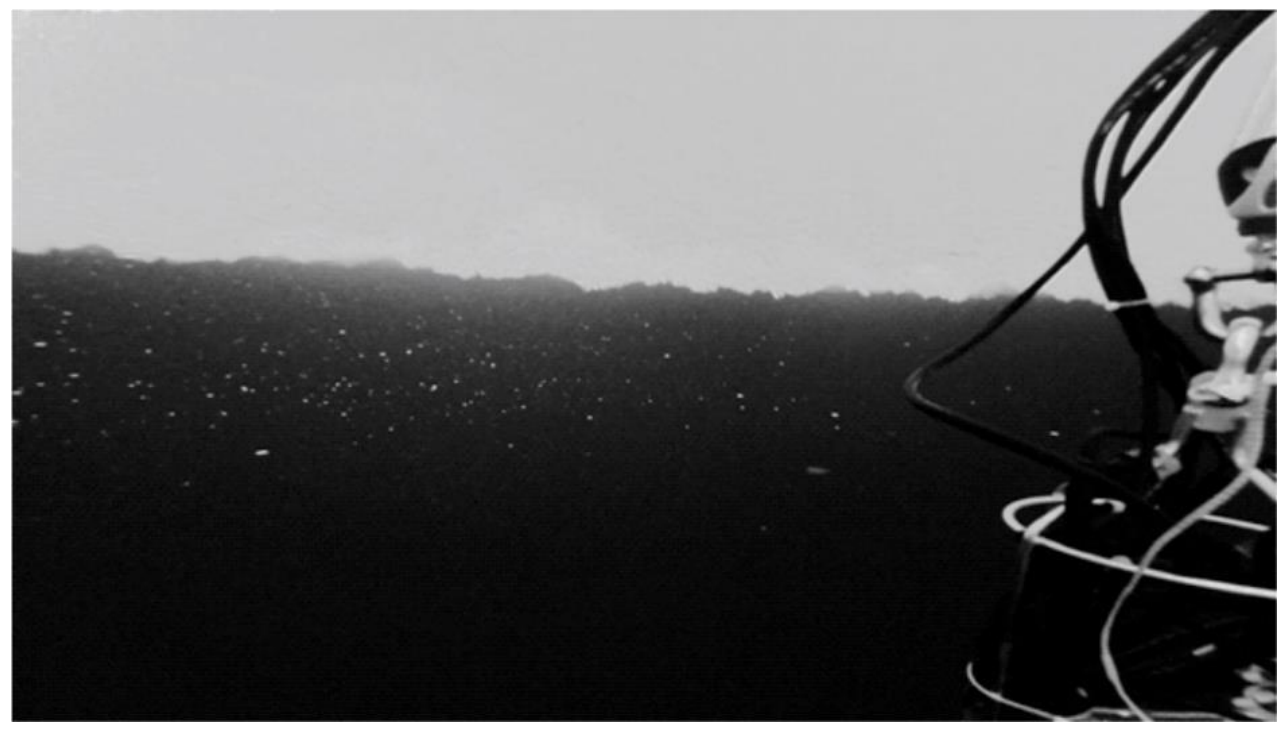

Figure 5 video still beneath ice showing suspended crystals (approximate horizontal field of view 5 m). The image has had its contrast manipulated to aid in identification of the crystals. 

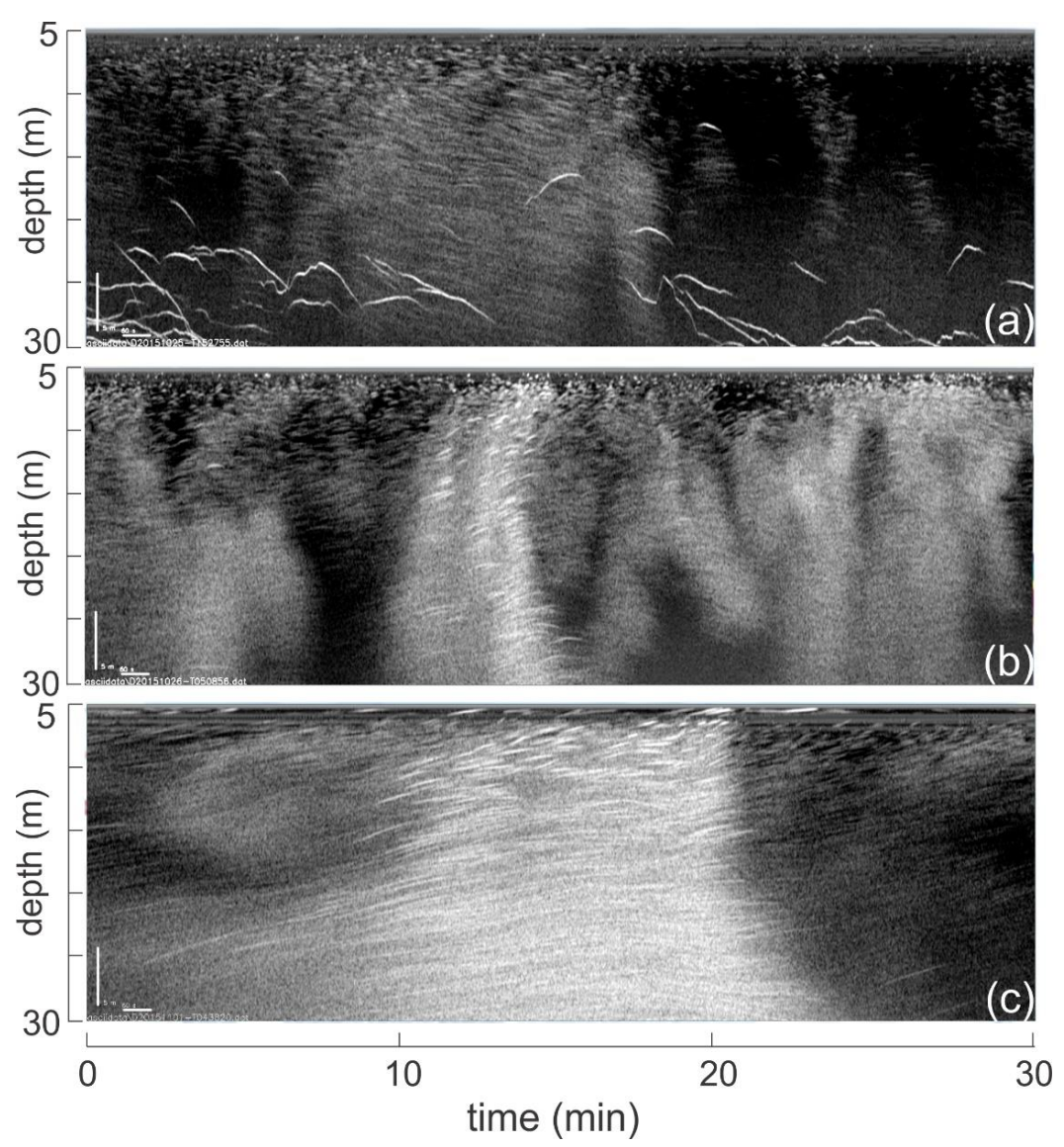

630 Figure 6 acoustic sounder images from different times showing platelets rising from depth. Each panel is 30 minutes wide and $25 \mathrm{~m}$ deep (scale bar bottom left show $5 \mathrm{~m}$ vertical and $60 \mathrm{~s}$ horizontal scale). A diagonal corner-to-corner path represents a rise speed of $14 \mathrm{~mm} \mathrm{~s}^{-1}$. The segments come from (a) $250 c t 2015$ at 1528 UTC, (b) $260 c t 2015$ UTC at 0509 and (c) 1nov2015 0438 UTC. 


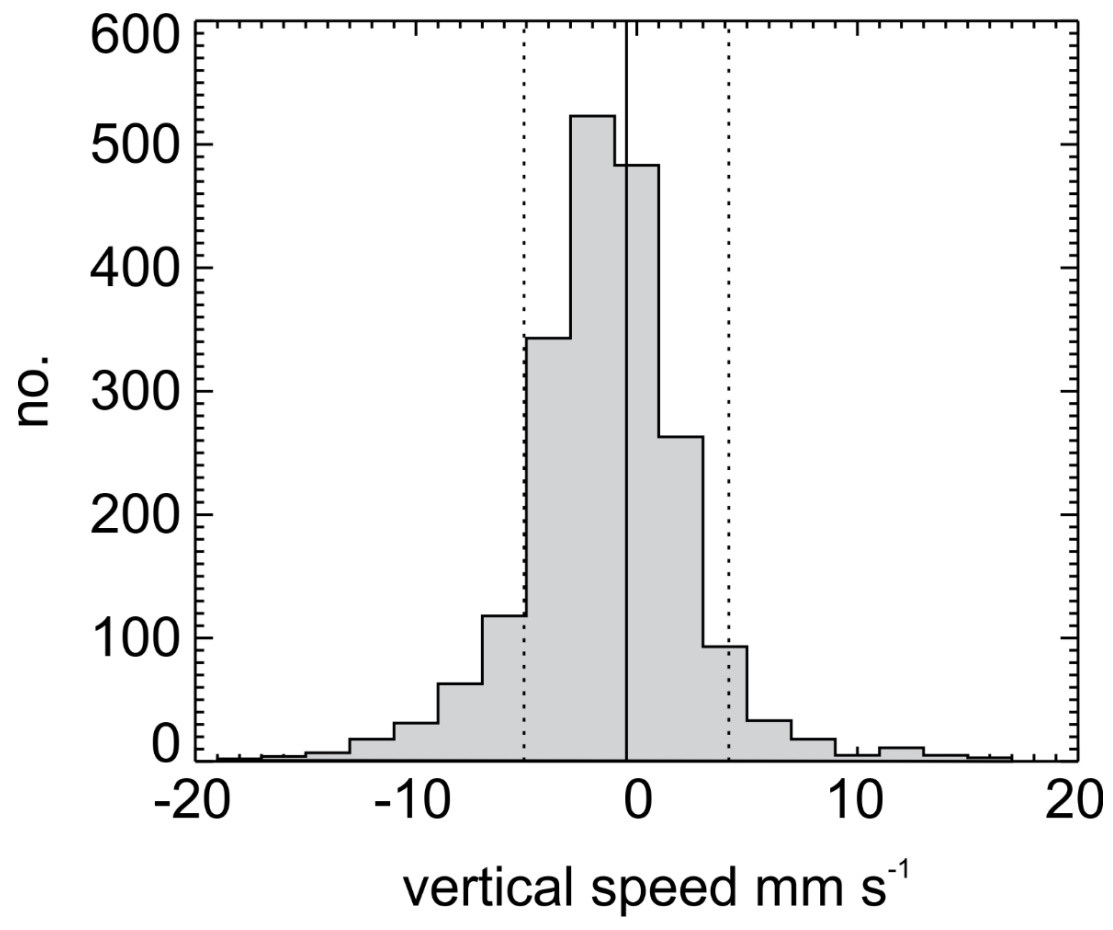

Figure 7 vertical velocity derived from echograms, where the solid vertical line is the average value and the dashed lines are +/-1 one standard deviation. Negative speed is upwards. 
640

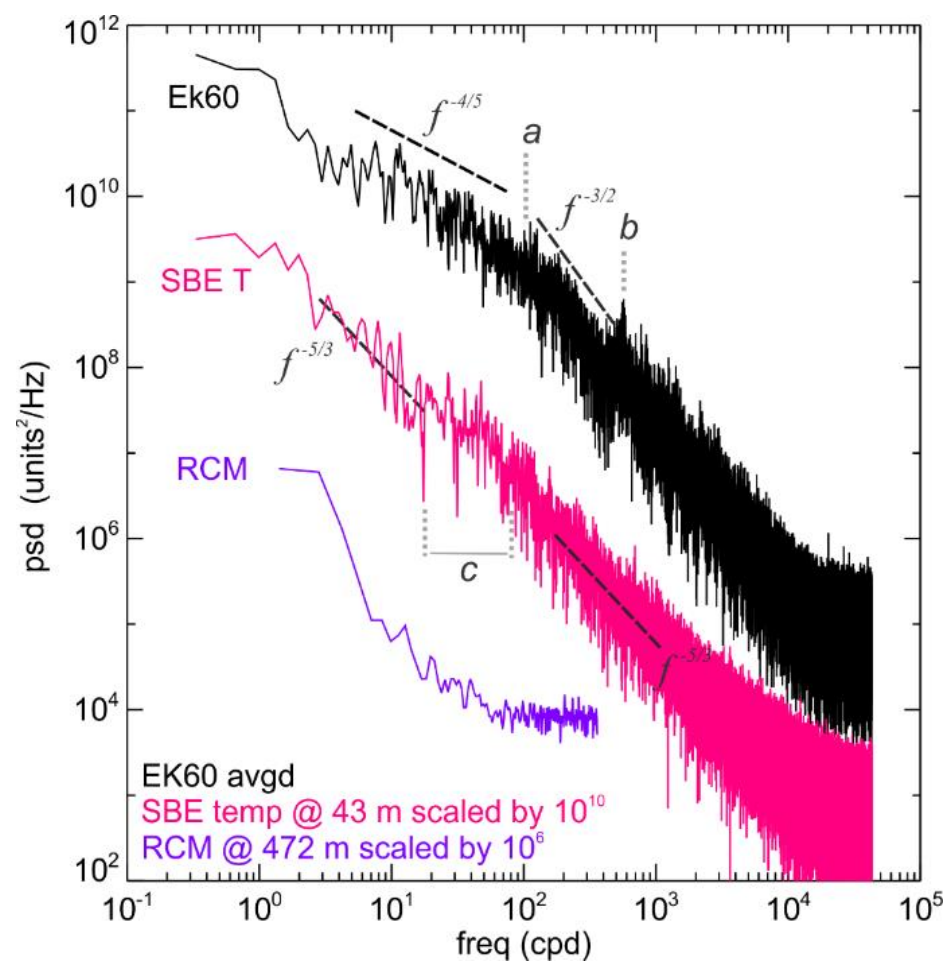

Figure 8 Frequency distributions displayed using apparent power spectral densities showing the vertically averaged acoustic backscatter (EK60), the temperature at $43 \mathrm{~m}$ and the current speed at $472 \mathrm{~m}$. The spectra are scaled to sit close by one another. Indicative frequency slopes and annotation are discussed in the text. 


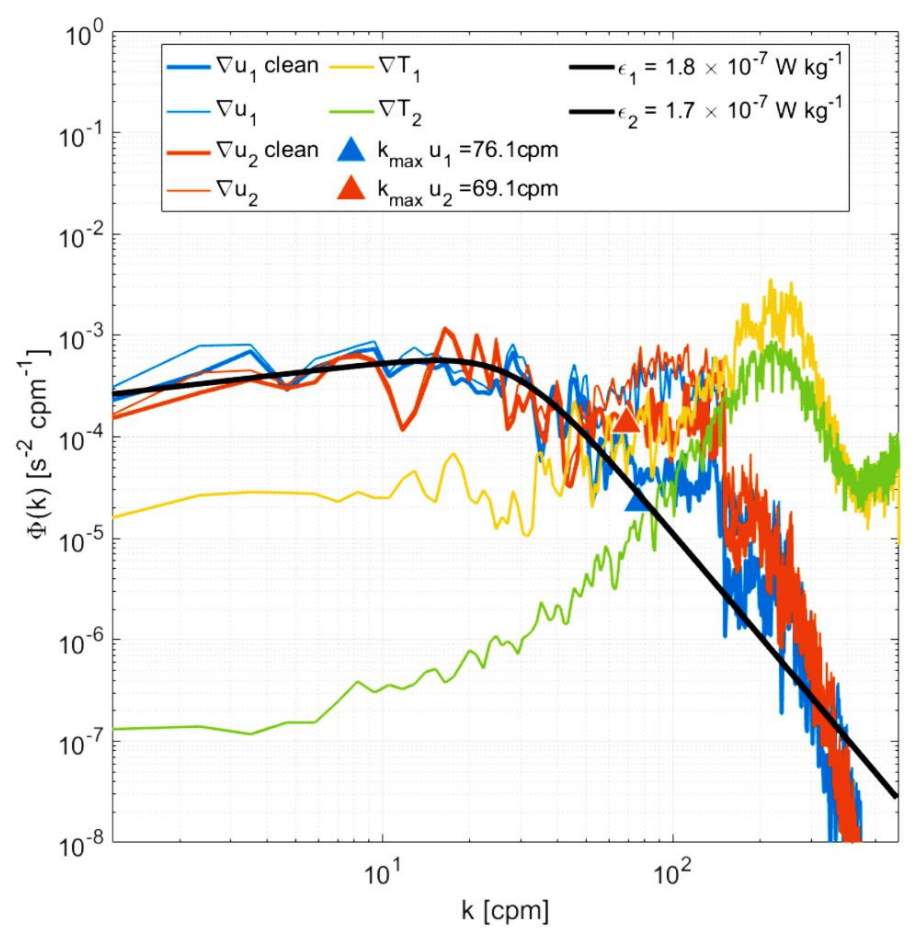

655 Figure 9 VMP microstructure example spectra showing temperature gradient $\left(\nabla T_{1,2}\right)$ and microscale velocity shear $\left(\nabla u_{1,2}\right)$ where the thin and thick lines show raw and filtered response. The black line is modelled energy spectra distribution for $\varepsilon=1.6-1.7 \times 10^{-7} \mathrm{~W} \mathrm{~kg}^{-1}$. The signal to the right of the triangles is amplified noise (Wolk et al., 2002). 
https://doi.org/10.5194/tc-2020-249

Preprint. Discussion started: 12 October 2020

(c) Author(s) 2020. CC BY 4.0 License.

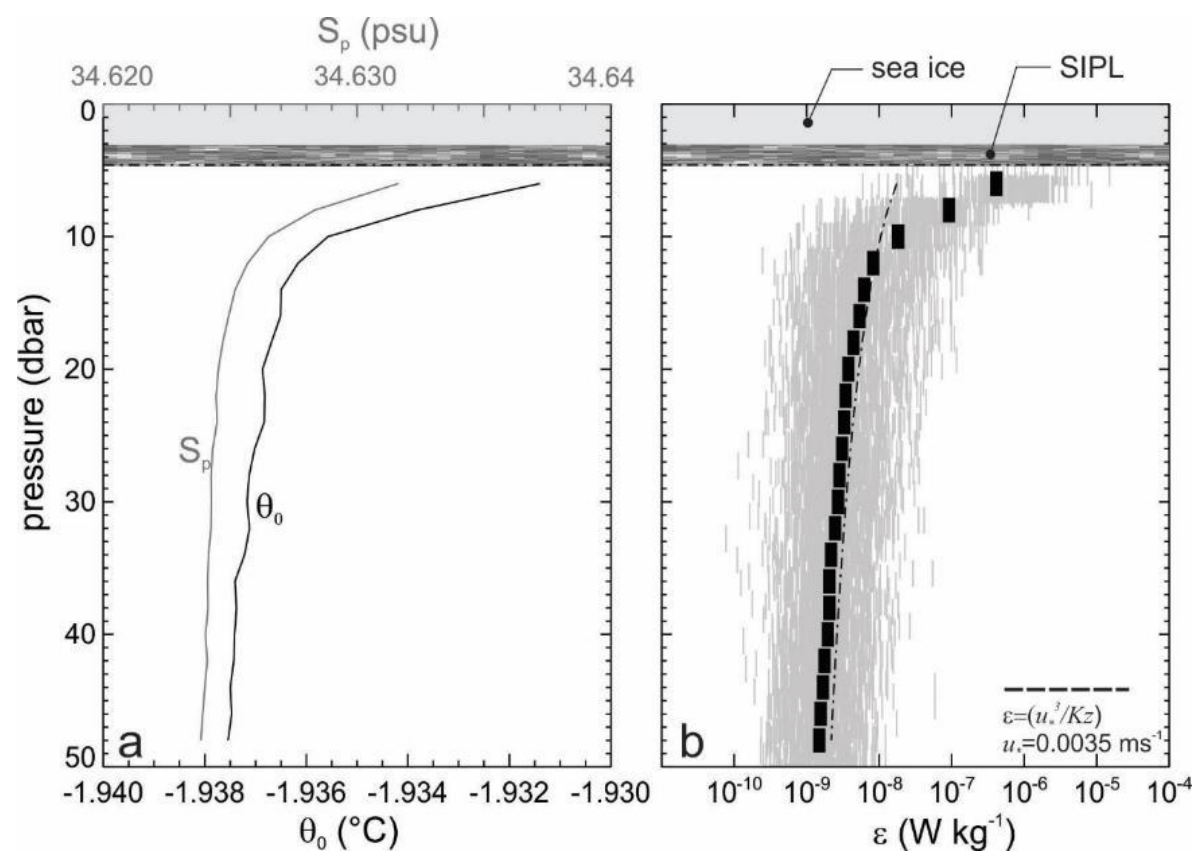

Figure 10 Averaged microstructure profile data over the top $50 \mathrm{~m}$ showing (a) time-averaged potential temperature $\left(\theta_{0}\right)$ and salinity $\left(S_{p}\right)$ and $(b)$ time-averaged turbulence dissipation rate, the individual samples and the shear-only scaling for $\varepsilon$. Both panels include the sea ice beneath hydrostatic zero and SIPL. 


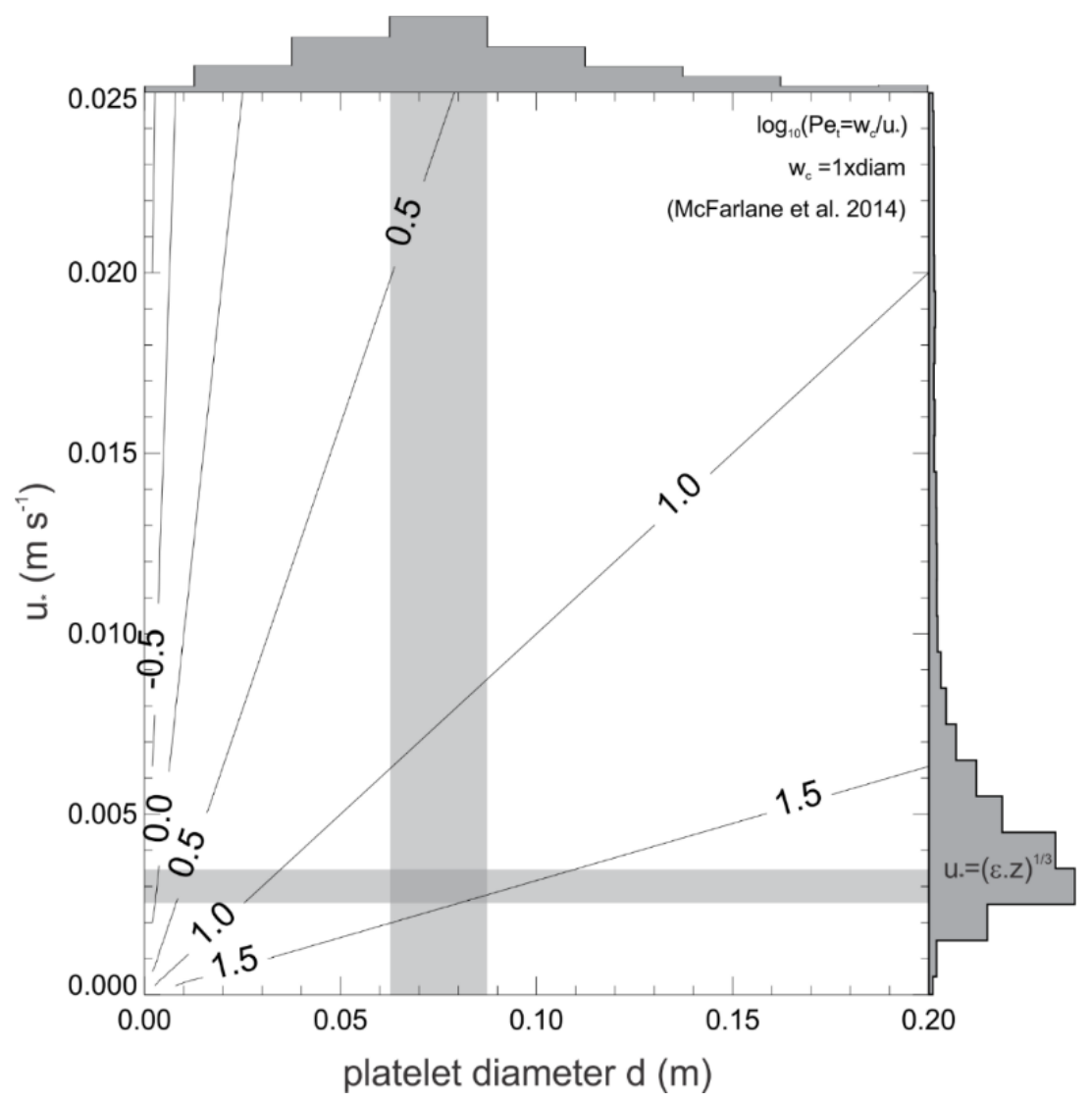

Figure 11 Variation of $\log _{10}\left(\mathrm{Pe}_{\mathrm{t}}\right)$ as a function of platelet size (i.e. diameter) and boundary layer turbulent velocity scale $u *$ showing approximate distribution and location of present results. The key assumption here is that the rise speed scales with diameter (see text) based on freshwater results from McFarlane et al. (2014). The diameter distribution is taken from Figure 4 and the $u^{*}$ distribution is from Figure 10 assuming the velocity scales with $(\varepsilon z)^{1 / 3}$. 

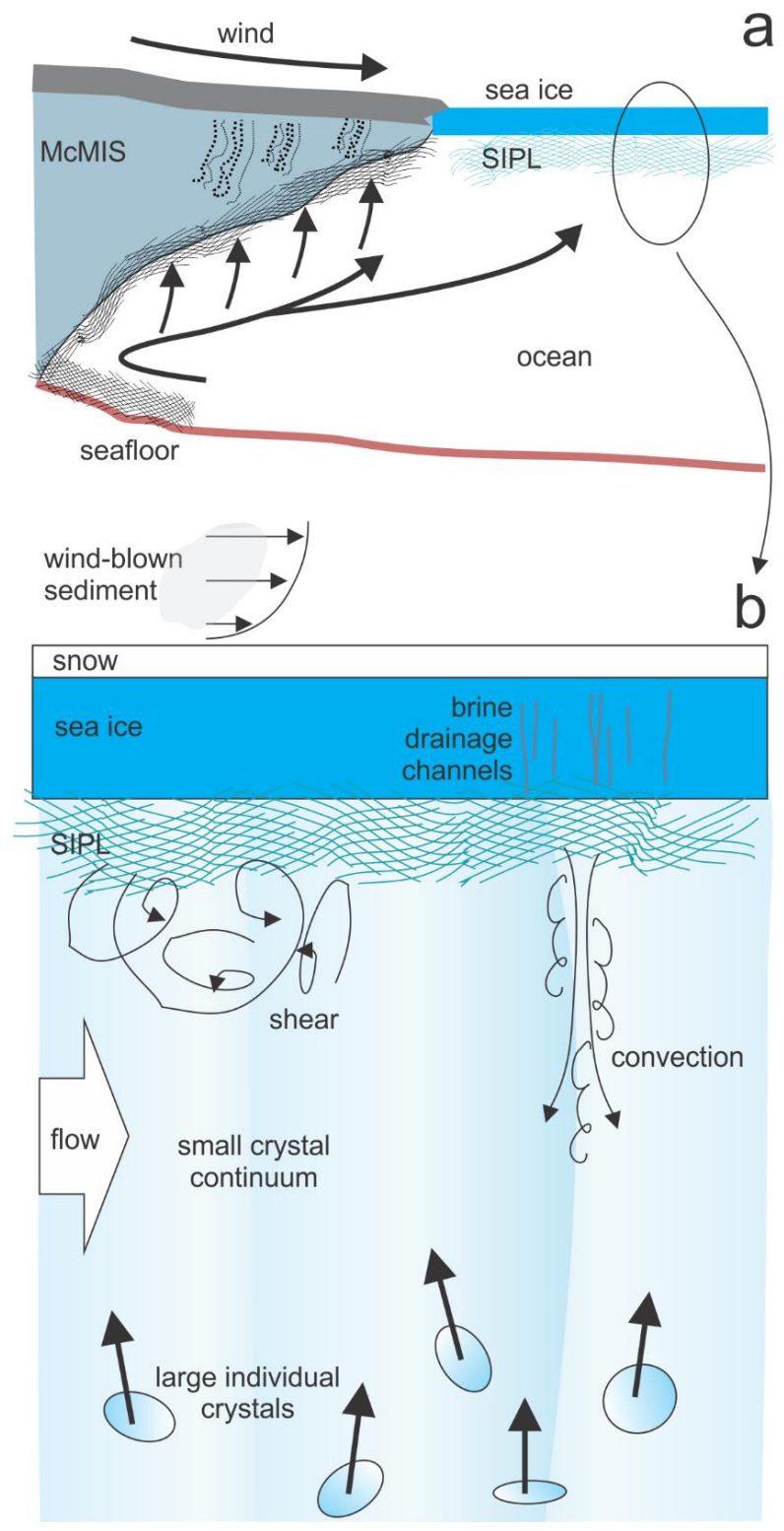

675 Figure 12 (a) elevation sketch of the ISW cavity and plume and how it might interact with a sediment-cycling system. (b) Ice/SIPL/Ocean boundary layer structure. 